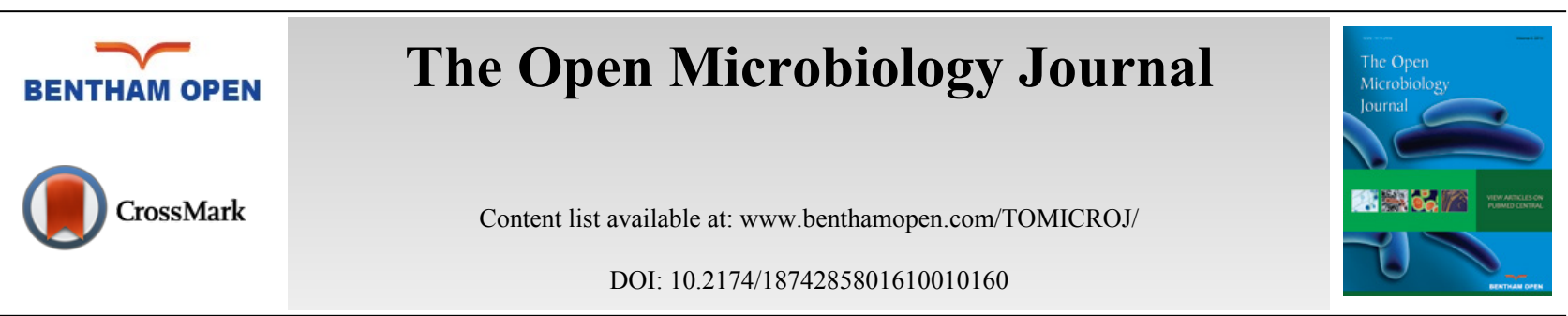

BOOK REVIEW

\title{
Book Review: Manual of Childhood Infections
}

\author{
Angel Cid Arregui* \\ German Cancer Research Center (DKFZ) Im Neuenheimer Feld 280, 69120 Heidelebrg, Germany
}

The fourth edition of this manual appears nearly five years after the third edition was published. It has been updated and re-written with the aim of improving the evidence-based management of pediatric infections. Emerging infections, nosocomial infections and antimicrobial resistance are covered in new chapters and updated existing ones. The new edition is also aimed at increasing the international projection of its contents. References, abstracts and learning points have been updated. This easily readable book is relatively close to fulfill the editors' aim to provide a reference book on childhood infections.

The book comprises 126 chapters distributed into two parts: Section 1 Clinical Syndromes (chapters 1-41) and section 2 Specific Infections (chapters 42-126). In addition, it contains eleven color plates, four appendixes, symbols and abbreviations, an index and a foreword. The chapters are authored by a total of 156 contributors. This edition was organized by 29 section editors, of which 20 were also chapter contributors. Section 1 covers antimicrobial drugs from mechanism of action to antibiotic resistance and antimicrobial stewardship in the first five chapters. Chapter 6 to 41 deal with a wide range of topics from gram-positive/gram-negative infections to zoonoses, from congenital to sexually transmitted infections, from cardiac infections to upper respiratory tract, urinary tract infections and encephalitis. Scattered throughout this section are chapters concerning systemic and unspecific complications of infectious origin: chronic fatigue, toxic shock and sepsis syndromes, pyrexia and rash. Further, a few chapters of this section are about more general topics, such as laboratory diagnosis of infection, control of infections in the hospital, emerging infections, refugees and adopted children, immunocompromised and immunodeficient children.

Section 2 contains 85 chapters approaching viral, bacterial, fungal and zoonotic infections combined indiscriminately. As an example, this section starts with Adenovirus (chapter 42), followed consecutively by Amoebiasis (43), Anaerobic infections (44), Arboviruses (45), Ascariasis (46) and so on. The chapter on Cytomegalovirus (61) is preceded by Cryptosporidiosis (60) and followed by Dermatophytoses (62). Likewise, Malaria (87) is followed by Measles (88) and Meningococcal disease (89).

Noteworthy, the criteria followed for the distribution of the topics in both sections seems to be mainly in the alphabetic ordering, but with many exceptions. For instance, in section 1 the two chapters on Gram bacteria and infections (27-28) are between Rash (26) and Refugees (29) and Ocular infections have been placed between Enlarged lymph nodes and Immunocompromised children, thus breaking the alphabetic sequence. The arrangement of such variety of topics in an alphabetic order seems inappropriate because it makes the contents of the book appear erratic and somehow anarchic, since thematically unrelated topics are brought next to each other. A grouping based on the causative agent of infection plus a miscellaneous group would be more consistent and would make it easier for the reader to find the information needed. Further concerning the edition, there are a number of flaws improper of a book of this category. For instance, it is surprising the fact that acute otitis externa has been omitted in Section 1, an important defect, needed this is a common condition in the pediatric population. In turn, the book contains a chapter on prion diseases, which is out of place in a manual of childhood infections.

\footnotetext{
* Address correspondence to this author at the German Cancer research Center (DKFZ) Im Neuenheimer Feld 280, 69120 Heidelebrg, Germany; Tel: 496221 567109; Fax: 496221 564776; E-mail: a.cid@dkfz.de
} 
All in all, this is an interesting book that provides valuable and mainly updated information on childhood infections. However, it needs urgent editorial intervention to rethink and redesign its contents in order to make it a reference book on childhood infections.

\section{(C) Angel Cid Arregui; Licensee Bentham Open}

This is an open access article licensed under the terms of the Creative Commons Attribution-Non-Commercial 4.0 International Public License (CC BY-NC 4.0) (https://creativecommons.org/licenses/by-nc/4.0/legalcode), which permits unrestricted, non-commercial use, distribution and reproduction in any medium, provided the work is properly cited. 